\title{
Comparative Analysis of Morphological Changes in Mammary Gland in Cows when Treating Mastitis
}

\author{
Olga Pavlenko, Suleyman Suleymanov \\ Voronezh State Agrarian University named after Emperor \\ Peter the Great \\ Voronezh, the Russian Federation
}

\author{
Lyudmila Mironova \\ Federal State Budgetary Educational Institution of Higher \\ Education Don state agrarian university \\ Settlement of Persianovsky, the Russian Federation
}

\begin{abstract}
The results of clinical and histologic trials of a mammary gland in cows during purulent-catarrhal mastitis and treatment by an antibiotic are presented in the article. It is established that in case of clinical mastitis, cows experience oppression, the body temperature, pulse and breath increase, secretion of milk considerably decreases. In the structural organization of a mammary gland in cows, purulent expansion of alveolar partitions at the expense of the damaged epithelium catarrhal exudate occurs. In expanded alveolar cavities, there are purulent - catarrhal exudates. Treatment of a mammary gland quarter by antibiotic is followed by the improvement of the structural organization of fabric and existence of the residual phenomena in the form of expansion of the gleams, filling them with the secret and alveolocyte of cylindrical and prismatic forms. Therefore, structural changes of the tissue of mammary gland in cows with clinical mastitis under the influence of the inflammatory process lead to irreversible consequences, and after treatment by antibiotics these changes are fixed and characterized only by the processes of proliferation of parenchyma cells, loosening and proliferation of the connective tissue in alveolar partitions.
\end{abstract}

Keywords-cows, mammary gland, mastitis, histological changes, antibiotic

\section{INTRODUCTION}

The main task of the presenttime is to provide the population with high-quality and environmentally friendly livestock products. The main products of cattle breeding are milk and produced dairy products (oils, cheeses, sour cream, kefir, etc.). The disease of cows with mastitis leads to the decrease in milk productivity, change in the quality of milk and its physical and chemical properties. According to the data of B. L. Belkin, the disease of cows with mastitis leads to a decrease in milk yield during lactation from $3,0-10,0 \%$ to $20,0-25,0 \%$, with chronic mastitis, milk yield falls to 23,0 $30,0 \%$. Treatment, prevention are carried out mainly with the help of antibiotics. Currently, there is a lot of data on antibiotics, sulfanilamides used for the treatment of lactating cows with mastitis, irritate mammary gland tissue. For a long time they can stand out with a secret of both treated and healthy adjacent mammary gland lobes. Thus, they can get into the milk of humans and animals, exerting a negative effect on their health $[1,2,3]$.

At the same time, successful treatment does not allow one to fully restore the function of the mammary gland. In animals with mastitis, milk production is reduced by an average of
$10,0 \%$, and in $50,0 \%$ of cows with sick lobes of the udder atrophy.

In this regard, the task was to study in the comparative aspect the effect of antibiotics on the mammary gland tissue in cows with mastitis during lactation.

\section{MATERIALS AND METHODS}

Clinical studies were conducted on the basis of the dairy farm "Experimental station" and LLC NPK "Agrotech-Garant Berezovsky" of the Voronezh region. Diagnosis of clinical forms of mastitis in cows was carried out taking into account anamnestic data, clinical study of the animal and its mammary gland, trial milking, followed by organoleptic evaluation of the secret. Exhaled secret was evaluated by the colour, consistency, smell and the presence of impurities.

In the affected lobe of the udder, the antibiotic pharmoxidin at a dose of $20 \mathrm{ml}$ of the drug - was injected 2 times a day for 3 days with pre-milking secretion and processing of $70,0 \%$. The nipples were treated by $7 \%$ ethyl alcohol; the corresponding lobes served as the control ones. Before introduction, the drug was heated to $40^{\circ} \mathrm{C}$. After introduction of the drug, the tip of the nipple was squeezed with fingers and lightly massaged from the bottom up for 1-2 minutes for a better distribution of the drug.

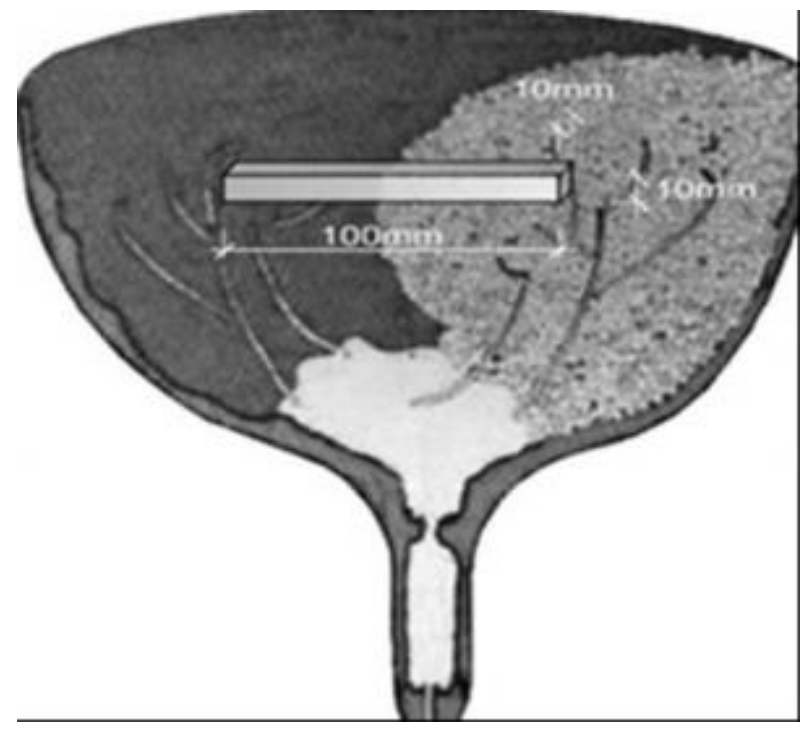

Fig. 1. Scheme of producing pathological material 
Samples of the mammary gland tissue for morphological studies were taken from the cows and with pathology + symmetrical lobes and pathology, treated with antibiotic + symmetrical lobes, $10.0 \times 1.0 \times 1.0 \mathrm{~cm}^{3}$ in size. Then the samples $\left(0.05-1.0 \mathrm{~cm}^{3}\right)$ were ablated in the middle part of the body from 6 cows with clinical mastitis killed at slaughter points for production needs. In 3 cows the lobes were treated, while in 3 cows the lobes remained untreated. The material was collected during the first hour after the slaughter of the cows. Thus the material of 6 cows was selected for histological examination according to the scheme (figure 1).

Tissue samples were processed in accordance with the methodological manual "Methods of morphological studies" $[4]$ and $[5,6,7,8,9]$.

\section{RESULTS}

In cows with purulent-catarrhal mastitis, the total condition was depressed. There was a refusal of food, body temperature increased to $41^{\circ} \mathrm{C}$, pulse, breathing, milk secretion sharply decreased; in one cow it stopped completely.

The affected parts of the udder increased in volume, the skin became reddish, hot, painful, swollen. During palpation of the affected lobes, focal or diffuse seals were found in the tissue thickness. The external inguinal (supra-parietal) lymph node located on the side of the affected lobes had a dense consistency and was painful during palpation. Mucus-purulent exudate containing clots of casein, cereal and streaks of pus, white, yellowish or reddish in colour were allocated during milking. In the selection of pathological material, it was visually found that the lobes, which were treated with antibiotic, were yellow-brown colour, the cut was moderately moist, somewhat dry, symmetric, of greyish-pink colour. The surface of the lobe section that was not treated was visually swollen and flushed, and the colour differed from the healthy symmetrical lobes.

On the histological sections of the mammary gland of the cows with clinical mastitis during lactation, it was found that the parenchyma of the gland consisted of a system of excretory ducts and end secretory sections. There was a rebirth of the alveoli epithelium, some of them very much expanded and torn with the formation of cavities filled with exudate, with an abundance of fat and milk inclusions, mainly polymorphic cells. At the same time, in the structural organization of the mammary gland lobes in the cows with purulent-catarrhal exudate, the expansion of the alveolar septum due to damaged epithelium occurred. Purulentcatarrhal exudates appeared in the expanded alveolar cavities, and the partitions of the alveoli were significantly unbroken (Figure 2).

At the same time, the mammary gland stroma was loosened, abundantly infiltrated with inflamematory cell exudates, which mainly consisted of lymphocytes, histiocytes, macrophages and a few polynuclears. Interlobular and interalveolar tissues were sometimes compressed and swollen, while blood and lymph vessels in inter-alveolar spaces were expanded (Figure 3). a)

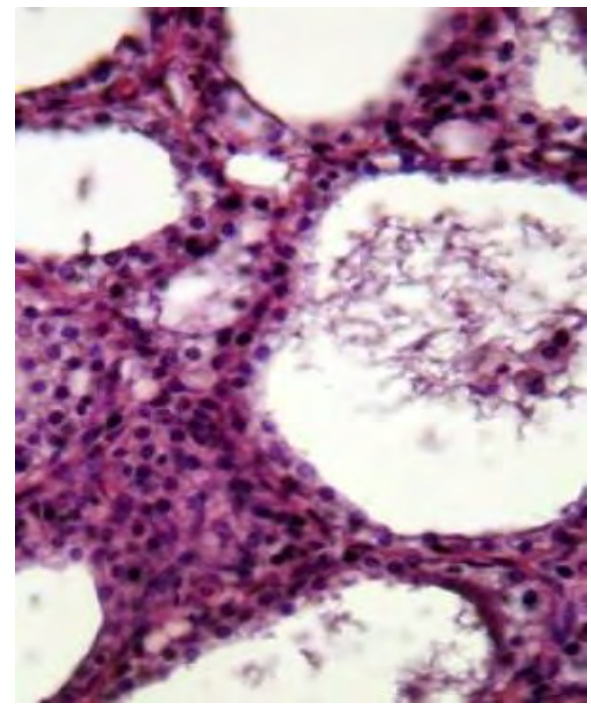

b)

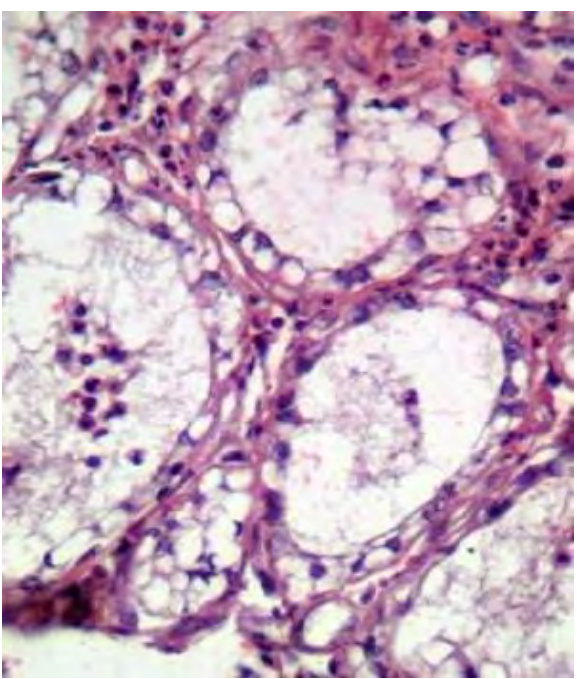

c)

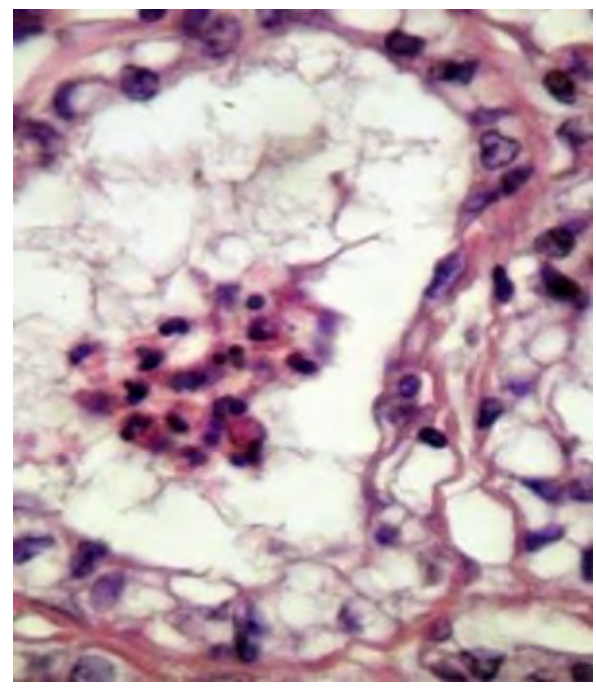

Fig. 2. Structural organization of the alveoli of the cow's mammary gland with purulent-catarrhal exudate: a) expansion of the alveolar septum due to the damaged epithelium; b) fragmentation of the alveolar septum; c) expansion of the alveolar cavity with purulent-catarrhal exudate. Hematoxilin-eosin 
a)

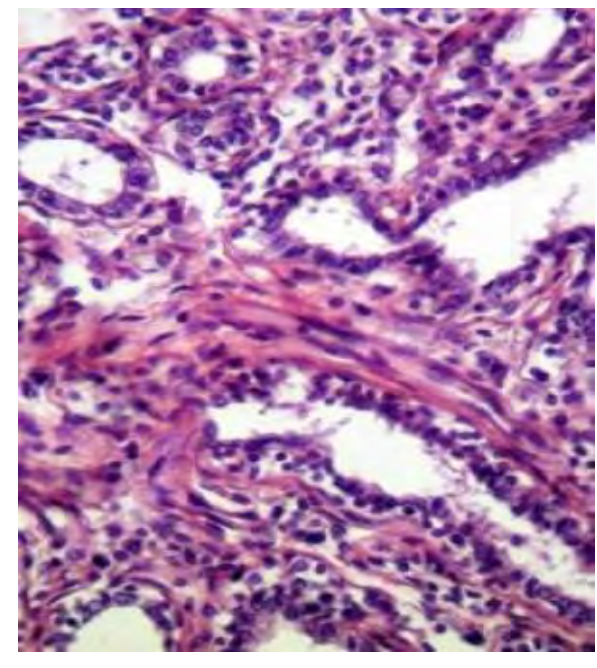

b)

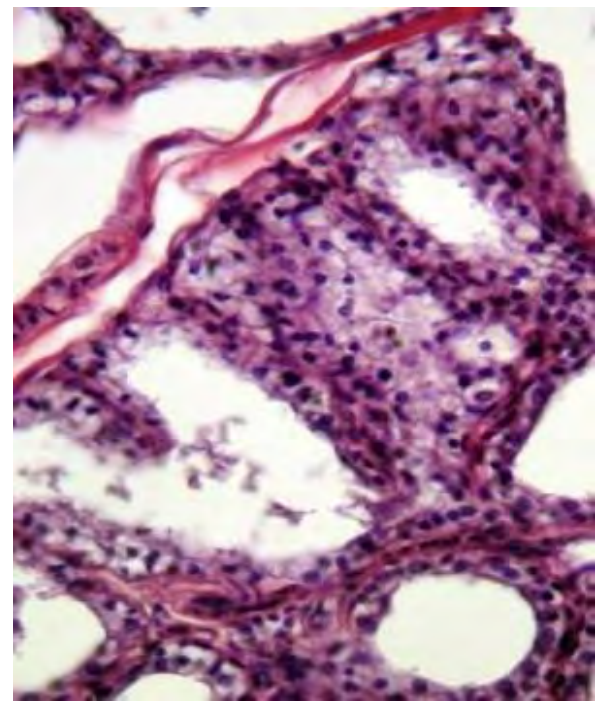

c)

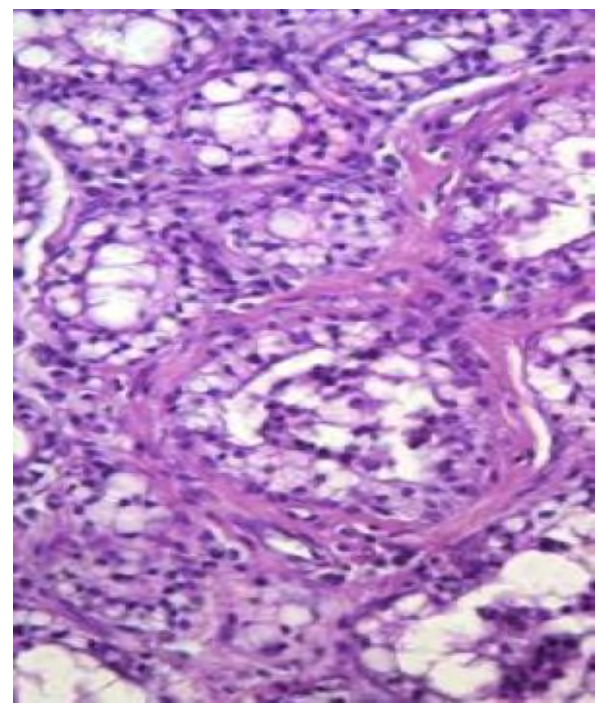

Fig. 3. The structural organization of the stroma of the alveoli of the share of the cow's breast with purulent-catarrhal exudate: a) infiltration of the stroma of the alveoli with inflammatory cell exudate; b) loosening and swelling of the stroma of the alveolar septum; c) compaction of the alveolar septum. Haematoxylin-eosin.

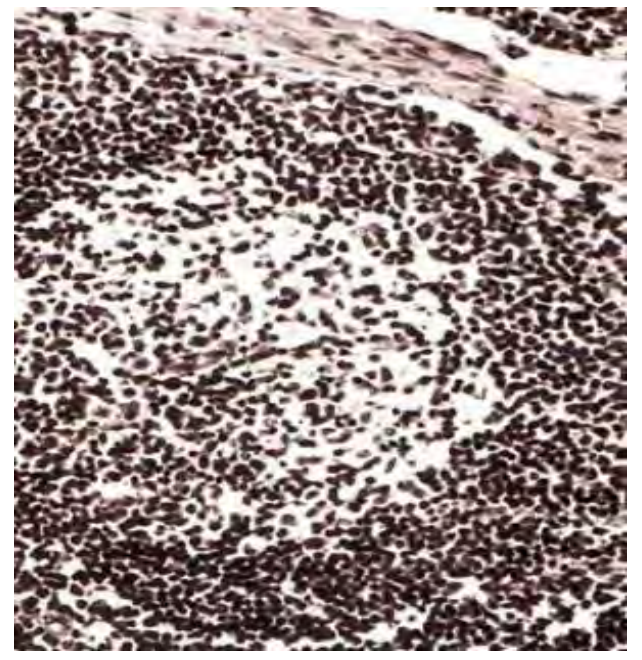

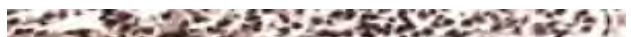

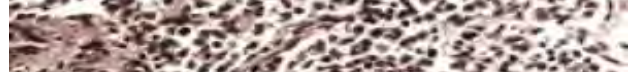

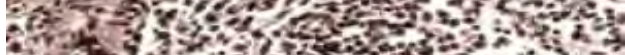

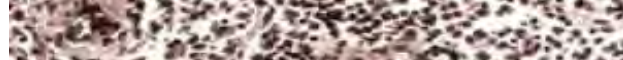

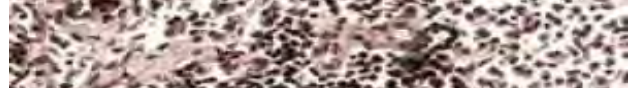
3. 3. -20 . ind?

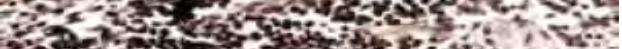

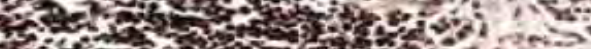

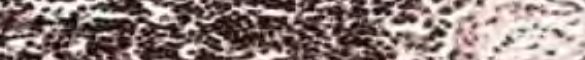
trituse

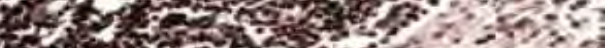

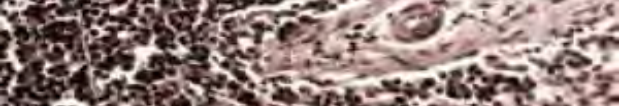

b)

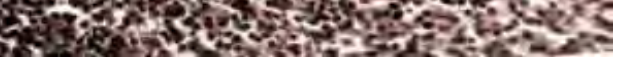

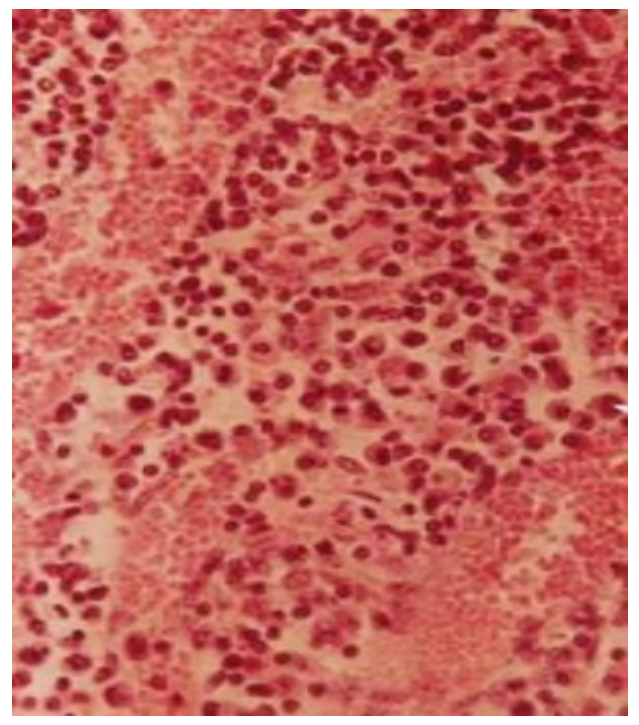

Fig. 4. The structural organization of the lymph node of the mammary gland in a cow with clinical mastitis: a) hydropic capsule of the lymph node against the background of a pronounced lymphoid follicle with a reactive centre; b) swelling of the trabecula and the edge sinus; c) the brain cords of the node, infiltrated by the shaped elements of the blood. Haematoxylin-eosin. 
The regional lymph node of the affected lobe was swollen, oedematous and elastic pale grey with a reddish tint. Microscopically marginal sinus was enlarged and contained single cellular elements. In the parenchyma of the node, the follicles did not have a clear boundary, merging with each other, forming a continuous mass of lymphoid tissue, imperceptibly passing into the brain cords. In the intermediate sinuses on the background of cerebral strands, the expansion of blood capillaries in the form of haemorrahages was observed (Figure 4).

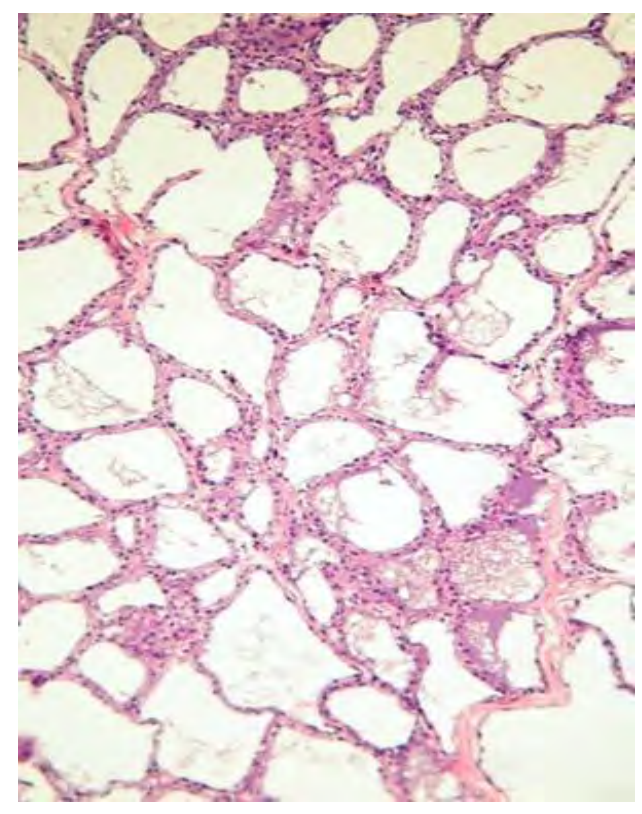

a)

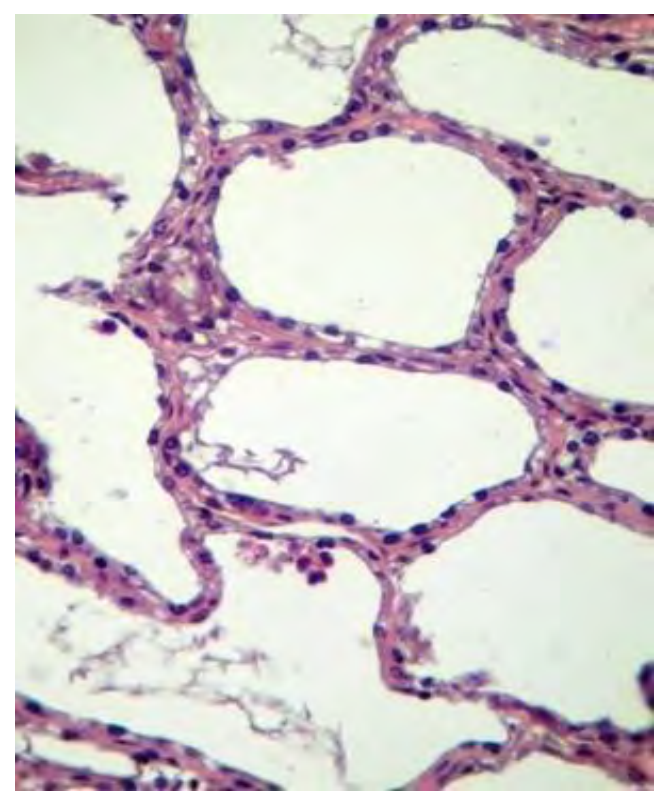

b)

Fig. 5. Structural organization of the unaffected symmetric lobe of a mammary gland of a cow with clinical mastitis: a) developed alveolar tissue of the mammary gland; b) different functional activity of alveolar cells. Haematoxylin-eosin.

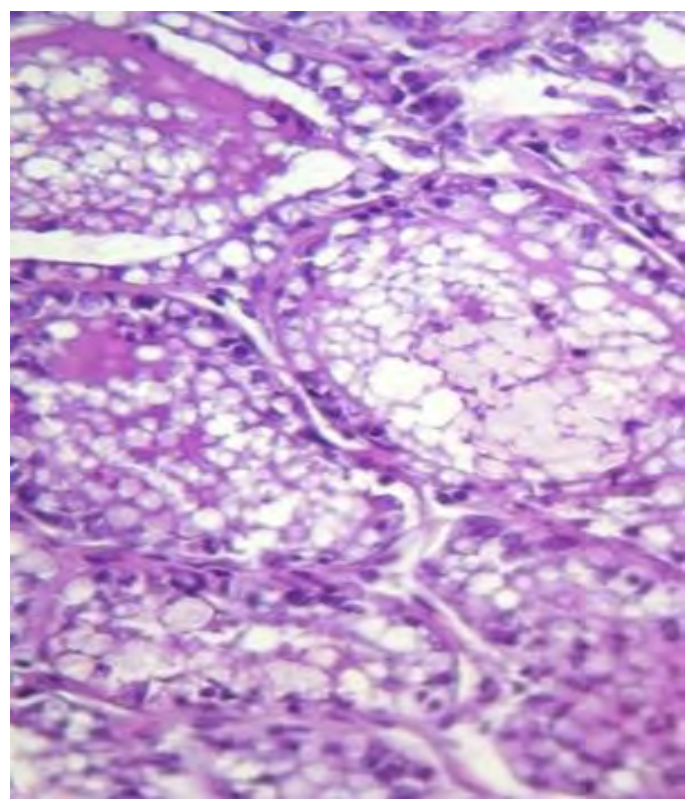

a)

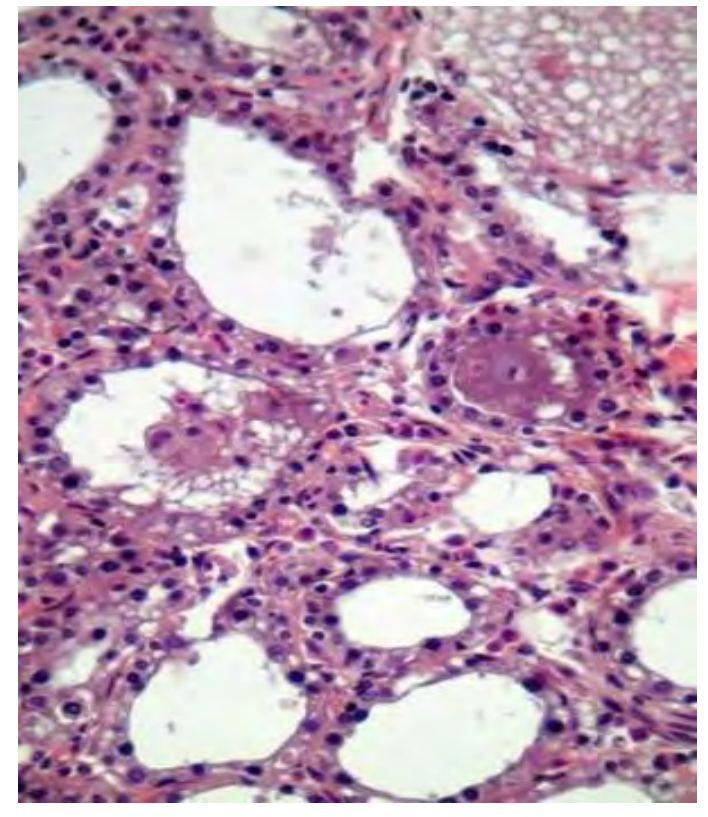

b)

Fig. 6. The structural organization of the lobes of the mammary gland of a cow treated with antibiotic: a) alveoli filled with secretions; b) residual inflammatory infiltrates in the parenchyma of the mammary gland. Hematoxylin-eosin. 
From the symmetric to unaffected lobes of the mammary gland, its structural organization was in the normal range with a well-developed glandular tissue. The structure of the lobules was non-uniform, reflecting different degrees of functional activity of the mammary gland, and the shape and size of the alveoli epithelium were directly dependent on the activity and stage of the secretory cycle [10] (Figure 5).

In the lobes in which the antibiotic was introduced the alveoli lumen was significantly expanded, filled with a secret, the alveolocytes acquired cylindrical and prismatic shape, and their vacuolation was also noted. In this case, the alveolar septum was sometimes expanded due to loose connective tissue and blood capillaries. Single somatic cells in the state of dystrophy floated in the alveolar fluid (Figure 6).

The walls of the end parts of the gland consisted of a single layer of secretory epithelium and myoepithelial cells. The cells of the wall of the alveoli had a prismatic, flat shape, and sometimes vacuolated and significantly rejected from the basement membrane of the alveoli. The structure of the tissue and its germination by connective tissue were more clearly expressed.

\section{DISCUSSION}

The inflammatory process that occurs in the mammary gland develops in the same forms and according to the same laws as in any organ. However, there are morphological features of the structure of the mammary gland that should be taken into account: first of all, the level of functional tension; density of blood and lymph vessels, the presence of a large number of anastomoses between them; relatively high availability for microbes.

According to many scientists, depending on the severity of the inflammatory process in the mammary gland, various morphostructural changes in its tissues are observed [11].

Konopeltsev I.G. [12] notes that in any form of mastitis there are dystrophic processes in the tissues of the mammary gland. Restoration of the structures of the glandular tissue occurs by replacing them with connective tissue and they become irreversible.

At the same time, a number of scientists claim that the epithelium of the alveoli and ducts is primarily affected against the background of proliferation of the connective tissue, there is a swelling of lactocytes that die and reject [13].

In acute purulent-catarrhal mastitis, purulent-catarrhal exudate in the presence of purulent cells, histiocytes and blood cells is found in the tank and milk passages. There is a strong hyperemia of the mucous output pathways, swelling and growth of the connective tissue of the milk tank and its infiltration by cellular elements [14].

In the affected lobules, the alveoli are of different sizes, polymorphic. They contain pinkish mass, and the alveolar epithelium is polymorphic, often clarified and desquamated. Interlobular septa are thickened, hyperemic, rich in immature connective tissue and lymphoid cells. Among the stromal elements, polyblasts, histiocytes, mast cells, and sometimes macrophages are often found [15].

Other morphological differences in the mammary gland in inflammation were observed by Dudko I.S. et al. [16]. In their opinion, the features of mastitis in cows should include an increased number of dilated lymph vessels in the mammary gland; focal hyalinosis of collagen fibres of interlobular, interalveolar and perivascular tissues; the presence of a significant number of cystic cavities of glandular structures; the inclusion of fat and hemosiderin in the cytoplasm of tissue cells; vacuolation of histiocyte cytoplasm.

\section{CONCLUSION}

These studies found that in case of clinical mastitis in cows the oppression of the general condition was observed; body temperature, heart rate and breathing increase. There is a significant decrease in milk secretion. Muco-purulent exudate containing clots of casein, cereal and streaks of pus, white, yellowish or reddish in colour stood out from the affected lobes. The affected lobes increased in volume, the outside acquired a reddish colour, became hot, painful and oedematous. Regional lymph nodes had a dense consistency and were painful at palpation. Microscopically marginal sinus enlarged and contained single cellular elements. In the intermediate sinuses on the background of brain weights, the expansion of blood capillaries in the form of haemorrhages was observed.

In the structural organization of the mammary gland lobes in cows with purulent-catarrhal exudate, the expansion of alveolar septa due to damaged epithelium occurred. In advanced alveolar cavities appeared purulent-catarrhal exudates, and the walls of the alveoli were significantly unbroken. In the pathology of the stroma of the mammary gland loosened, infiltrated inflammatory cell exudates containing lymphocytes, histiocytes, macrophages and a few polynuclears. Treatment of the mammary gland lobes with antibiotic was accompanied by the improvement of the structural organization of the tissue and the presence of residual phenomena in the form of expanding gaps, filling them with secret alveolocytes of cylindrical and prismatic forms. Alveolar septum sometimes expanded due to loose connective tissue and blood capillaries.

Consequently, the structural changes in the mammary gland tissue in cows with clinical mastitis under the influence of inflammation lead to irreversible consequences and after treatment with antibiotics, these changes are only fixed and characterized by the processes of proliferation of parenchyma cells, loosening and proliferation of connective tissue in the alveolar septum.

\section{REFERENCES}

[1] B.L. Belkin, L.A. Cherepakhina, T.V. Popkova and E.N. Skrebneva, "Diagnosis and non-traditional methods of treatment of subclinical mastitis of cows", Vestnik OrelSAU, p. 31. 
[2] N.S. Belozertseva, S.V. Fedotov, A.V. Derinov and V.A. Boltenkov, "Features of early diagnosis of subclinical mastitis in cows", Bulletin of the Altai State Agricultural University, No. 3 (103), 2013, pp. 104108.

[3] R.K. Shaev, Effect of biogenic stimulants on milk composition in the treatment of subclinical and acute serous form of mastitis in cows, 2005, 271p.

[4] S.M. Suleymanov, Fundamentals of morphological methods of research:manual for students of higher education, students majoring in "Veterinary", "Zootechnics", Voronezh state agricultural university, Voronezh, 2015, $128 \mathrm{p}$.

[5] J.J. Bozzola and L.D. Russell, Electron Microscopy, Principles and Techniques for Biologists, Boston, Jones and Bartlett Publishers, 1992.

[6] D. Dabbs, Diagnostic Immunohistochemistry (2nd edit.). Philadelphia, Churchill Livingstone, Elsevier, 2006.

[7] Ch.Genoud, G.W. Knott, K. Sakata, B. Lu and E. Welker, "Altered synapse formation in the adult somatosensory cortex of Brain-Derived Neurotrophic Factor heterozygote mice”, J.Neurosci, 2004, 24, 10, p.2394-2400.

[8] M.A. Potts, "Method for location specific histological features for electron microscop", J. Roy. Micr. Soc., 1965, 85,1, pp. 97-102.

[9] G. Robinson and T. Gray, Electron microscopy 2: Tissue preparation, sectioning and staining, in: Theory and practice of histological techniques. (eds. Bancroft JD, Stevens A.), Churchill livingstone, New York, 1990, pp. 525-562.
[10] O.B. Pavlenko, S.M. Suleimanov, L.P. Mironova and V.N. Vasilenko, "Structural organization of the mammary gland in lactating cows", Veterinary pathology, 2012, vol. 40, No. 2, pp. 15-17.

[11] V.A. Parikov, Mastitis in cows: guidelines, Integrated environmentally safe system of veterinary protection of animal health, Moscow: FGNU Rosinformagrotech, 2000, $300 \mathrm{p}$.

[12] I.G. Konopeltsev and V.N. Shulyatyev, Inflammation of the udder of cows: textbook, Kirov-St. Petersburg: VGSA, 2010, 353 p.

[13] L.I. Kundrukova and V.V. Patlasova, "Morphological response of different fractions of the udder lobes to the inflammatory process in one of them", Proc. scientific. articles. Sverdl. Agricultural Institute, 1982, vol. 64, pp. 52-56.

[14] L. Mosyakov, "Mycological, histological and histochemical studies of udder tissue in mastitis of cows", Issues of disease prevention in animals, 1983, pp. 7-13.

[15] S.M. Suleymanov, V.V. Podberesky and V.I. Slobodyanik, "Histostructure of mammary gland in cows with mastitis treated with endometrin", Materials of all-Russian scientific and methodical conference on obstetrics, gynecology and biotechnics of animal reproduction, Voronezh, 1994, pp. 243-244.

[16] I.S. Dudko, O.N. Yakubchak and V.Yu. Soroka, "On the morphology of the mammary gland of cows with mastitis", Diagnosis, pathogenesis, pathomorphology and prevention of diseases of animals Materials of All -Russian. scientific. methodic conf., Voronezh, 1993, pp. 121-122. 